\title{
Solving Real-Life Problems: Future Mobile Technology Sophistication
}

\author{
FARHAN SHAFIQ*, KAMRAN AHSAN*, AND ADNAN NADEEM* \\ RECIVED ON 13.03.2015 ACCEPTED ON 16.09.2015
}

\begin{abstract}
Almost all the human being real life concerned domains are taking advantage of latest technologies for enhancing their process, procedures and operations. This integration of technological innovations provides ease of access, flexibility, transparency, reliability and speed for the concerned process and procedures. Rapid growth of ICT (Information and Communication Technology) and MT (Mobile Technology) provides opportunity to redesign and reengineered the human routines' life activities process and procedures. Technology integration and adoption in routine life activities may serves compensatory mechanism to assist the population in different manner such as monitoring older adults and children at homes, provides security assistance, monitoring and recording patients vital signs automatically, controlling and monitoring equipments and devices, providing assistance in shopping, banking and education as well. Disasters happened suddenly, destroy everything indiscriminately. Adoption and integration of latest technologies including ICT and MT can enhance the current disaster management process, procedures and operations. This research study focuses the impacts of latest and emerging technology trends in routine life activities and surrounds their potential strength to improve and enhance disaster management activities. MT is providing a promising platform for facilitating people to enhance their routine life activities. This research argue that integration and adoption of mobile computing in disaster management domain can enhance disaster management activities with promising minimizing error, quick information assembling, quick response based on technology manipulation and prioritizing action.
\end{abstract}

Key Words: Mobile Technology, Technology Trends, Future Technology Trends, Disaster Management Technologies.

\section{INTRODUCTION}

1 technology that permits data transmission via computers without having physical connection and fixed location is known as MC. MC enables mobile devices to create, store, process, and access the information without having spatial and temporal constraints [1] . This type of combination of hardware (e.g. portable devices), communication technology (wireless networking), software or applications is called
MCS (Mobile Computer Systems). Flexibility of MC adds the great advantages to business or home user. MC change the way of human being routine life activities like shopping, entertainment, education, travelling, sale and purchase, social networking, banking, sports, public services, environment monitoring, weather updates, climate change monitoring and emergency or disaster situation handling. There are variety of application

\footnotetext{
* Department of Computer Science, Federal Urdu University of Arts, Sciences \& Technology, Karachi.
} 
available which supports above defined activities with great accuracy, efficiency and flexibility. As MT gained exponential growth in last decade consequently mobile software application also increasing in demand [2]. Due to the rapid development and increasing adoption and penetration of MTs at individual user and organizational level, new and challenging opportunities are available for mobile software developers to create mobile application that can be used in simple routine life activities like gaming, education, entertainment to enhancing shopping, advertising, social networking as well as to support the complex phenomena of banking, stock market, Money transfer, handling emergency and disaster situation, providing health assistance, sharing news and views, disseminating weather updates and climate related information, helping in location identification and navigation in addition with providing assistance to the impaired people. There are some factors which are playing key role in increasing adaptation of mobile computing phenomenon including Convergence of infrastructure, convergence of interoperable applications and services on an integrated machine [3].

This research encircles the latest MT trends and their adoption in solving real life problems and the focused domain of the research is the disaster management. This research considered disaster management as a real life problem and emphasizes the use of latest and forthcoming technologies including ICT and MT for solving disaster management problem and challenges. Many of the routine life issues that take too much time and seem tedious in nature can be easily carried out with minimum time consumption, without bothering queues and waiting, without physical appearance at the place of service provider. Furthermore, the use of mobile technology also enhance the process and procedures and make the whole activity more convenient, transparent, responsive, flexible beyond the time and space limitations. For example placing an order for a dress, food item, book or some electronic device through mobile application software is more easy and convenient. There is no need to go to shop and stores during working hour find out the availability of the required product and place the order and pay the cash for the selected items. The whole activity can be carried out by using mobile apps of the related stores, just search out the items, check the specification, place the order and make mobile payment for the purchase items. This activity no needs to visit the store with in working hours and carrying the paper and plastic money with us. Similarly many of the financial institutions and organizations provided their mobile based solutions for transferring money, credit details and financial assistance. Healthcare domain is also a growing field for using MT for monitoring and sharing patient's real time data as well as providing various healthcare facilities on mobile devices. Emergency situations are common in real life scenario and any emergency situation can be happen at any time. MT is also providing great assistance in emergency situation like natural and man induced disaster. Getting disaster early warning message on mobile devices can provide more time to prepare for the upcoming conditions. Sharing data including text, pictures and videos during disaster response can enhance the relief operations, optimized the resource gathering and resource allocation, minimize the response time and increase the information gain. Most of the latest technology trends including wearable technology, social networking, IoT (Internet of Things) and non touch interfaces are increasing technology trends in disaster management domain. This research focuses the most important and increasing phenomena of real life that is disaster management. The frequency and intensity of the natural disasters is increasing day by day around the globe [4]. Advances of MT development, growing adoption and penetration of mobile devices [5], alignment ability of MT and its sophistication with various human life concerns gives the opportunity to take assistance in managing disaster events in order to overcome communication and coordination issues during disaster response, sharing of real time information, tracking and monitoring objects with respect to time and locations, transferring immediate funds to victims, monitoring real time data and information disseminating by various interconnected objects through IoT, solving language problems, connect or rejoining the victim families. 


\subsection{Technology Advancements and Latest Technology Trends}

Rapid technology advancements and development is creating more and more opportunities for adoption and integration these latest technologies in optimizing our routine life activities. The current technology trends according to technology advancements and its sophistication are more interesting and appealing for solving real life problems. In literature review for this study we found various interesting articles related to increasing trends for technology adoption and integration for solving different types of real life problems. The past few years have witnessed important advances in emerging technologies including ICT, MT, sensor technology, wireless networks and many more. Various efforts have been made in the direction of technology integration for solving real life and simplify the process and procedures of routine life activities with the help of technology advancements. According to literature review followings are the latest technology trends.

(1) Wearable Technology [6]

(2) Internet of Things to Web of Things [7]

(3) Social Networking [7]

(4) Emergence of Mobile Cloud [7]

(5) Non Touch Interfaces [6]

(6) 3D Printing [6]

(7) Online learning and Massive Open Online Courses [8]

(8) eBooks, eNewspapers, eMagazines and interactive multimedia eTextbooks [8]

(9) Gamification of training and education [8]

(10) Virtualization of storage, desktops, applications and networking [8]

Following section of this research study presents above listed technology trends, their sophistications, adoption and penetration in current time.

\subsubsection{Wearable Technology}

Wearable computing can change the way of human life as they experiencing today. Wearable small sensors and gadgets are increasingly used in healthcare, sports and fitness. Wearable gadgets can monitor human health and fitness, can measure human physical activities, blood oxygen level, Sleep, managing chronic disease, could save human life, manage fitness programs. These gadgets ranging from reading and monitoring body temperature, motion, blood pressure, to heart rhythm. Theses gadgets are also using in sports and fitness [9]. While these gadgets not only helpful in monitoring sick patients, athletes and sports man but also beneficial for disaster victims too [10]. In short we can say that along with humans' natural senses, wearable technology is furnishing one more sense to human. Wearable technology is rapidly penetrating in human life and enhancing the quality of life for human beings [11]. Most of wearable sensor devices and their applications are using in Healthcare monitoring systems [12], medicine and rehabilitation [13], biomedical engineering [14], human body motion recognitions [15], measuring human behavior, smart clothing [16], crime scene investigation [17] and in emergency or disaster management, a situation where hands-free operations are required such as fire fighting and police operations [18], disaster response and recovery [19] and disaster rescue operations [20].

\subsubsection{Internet of Things}

The objective of creating the IoT is to setup an environment which is equipped with smart interconnected objects and placed in the various locations in the environment and be able to transmit information from one smart object to another smart object which makes environment smart and self aware. Smart environment including smart buildings, smart cities, smart transportation, and smart health can help in better serving mankind. IoT can help in managing our-self, our family members, our home, our city, our industry and our environment in better way which cannot be found before

Mehran University Research Journal of Engineering \& Technology, Volume 35, No. 3, July, 2016 [p-ISSN: 0254-7821, e-ISSN: 2413-7219] 
internet of things. By sensing the environment and accessing the information transmitted by embedded objects we can easily monitor new born babies with real time information about infant breathing, body temperature, body position, and activity. Similarly with the help of wearable sensor devices we can take care of our elder and handicapped family members, monitor their routine daily life activities and let fell them security and safety. Managing our homes by remote monitoring of appliances and devices installed in our homes such as controlling thermostats to heat our homes, switch on and off plugged in devices, track lost keys. Smart cities can be developed on the basis of IoT idea and this technology can effectively manage resources which are vesting in absence of proper management system. It provides traffic monitoring and sends real time information about traffic jams, accidents and alternative routes in case of any unfavorable situation. This can be achieved by M2M (Machine to Machine) interaction. Electricity can be used in efficiently, avoid driving in round and round in search of parking which save time and energy both. Control street lightning on the bases of weather conditions. Trigger early warning alerts and messages in case of any emergency situation like natural disasters. IoT is now widely using in assisting people in real life activities. Smart home and smart cities concept can help in better management of natural disasters challenges. Real time information dissemination, location based early warning messages and alerts automatically disseminate, tracking and monitoring of resources during disaster rescue and relief phase can provide great assistance in conducting rescue activities with maximizing real time information gain and can help in better decision making.

\subsubsection{Social Networking}

People like social networking which is increasing computing trends of the current era. Social networking gain popularity in the consequences of rapid advancements in wireless networks technology and increasing adoption of mobile devices like smart phones. It gives the anytime, anywhere connectivity with friends and family members. Information sharing, status updates, sharing of photos and videos and posting comments are the most popular and favorite activities of social networking users. According to the [21] guide top 10 social networking sites of 2013 are Facebook, Twitter, LinkedIn, pinterest, MySpace, Google+, DevlantArt, liveJoumal, Tagged, Orkut. Graphical representation is given below. This ranking is based on a September 2013 report by eBizMBA Rank; Facebook still tops the charts with an estimated 750 million unique visits every month. Twitter follows with 250 million, and LinkedIn goes in third with 110 million. Fig. 1 shows the popularity graph of the social networking sites according to the number of subscriber.

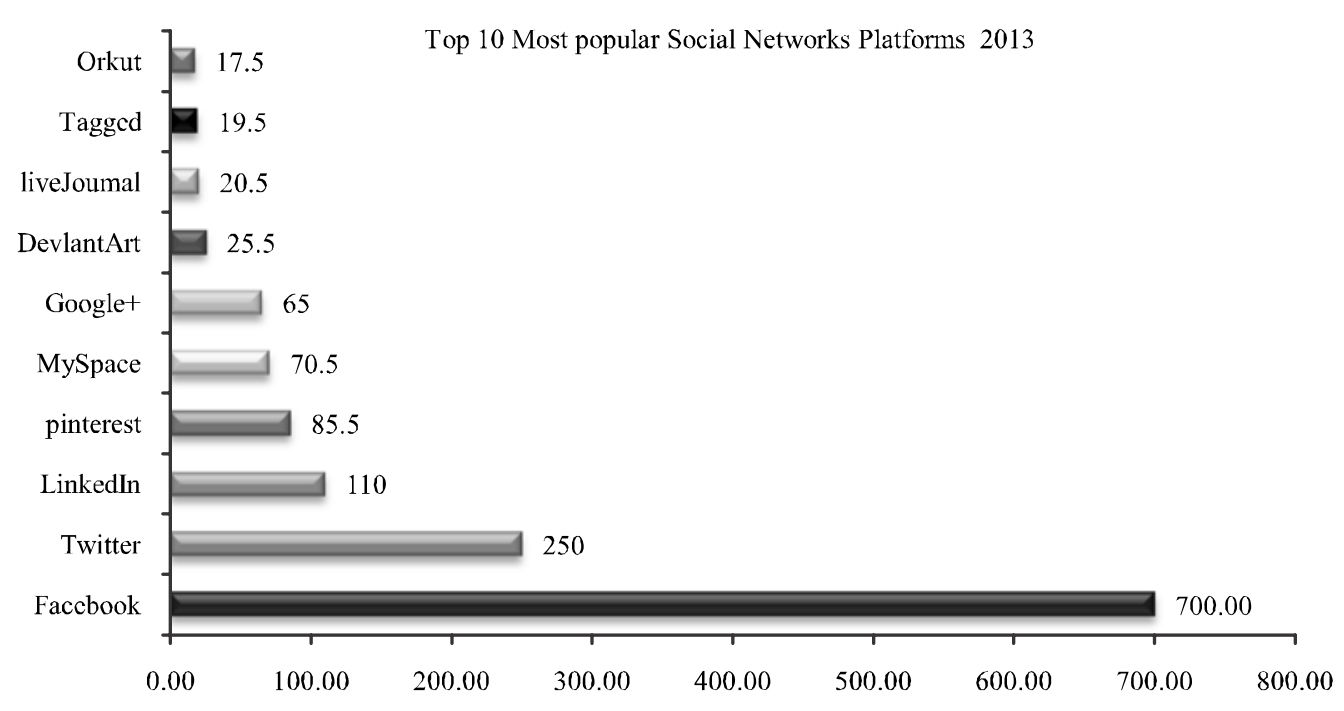

FIG. 1. TOP 10 SOCIAL NETWORKING PLATFORMS 2013 (SOURCE: [21]) 
Social networking is changing the way of communication not only in their routine day life but in during disaster which threaten human lives [22]. Social media is now helping in disaster management activities including sharing information about the current situation of the disaster affected region, rapid messaging for rescue help, crowd sourcing, disaster fund raising, increasing awareness of disaster preparedness and sharing photos and videos of trapped community and region. Use of social media in natural disasters is another face of coin. There are various examples of use of social networking platforms in disaster management activities and rescue operations in different parts of the world such as assisting in emergency preparedness [22], emergency situation awareness [23], crowd sourcing for disaster relief [24], information propagation in wildfire disasters [25], emergency knowledge management in earthquake disasters [26]. Following are some examples of use of social media in disaster management activities and operations.

\subsubsection{Emergence of Mobile Cloud}

Mobile devices are rapidly penetrating in human life, anywhere and Anytime computing facilities just because of rapid development of mobile devices hardware, software and wireless networking technologies but mobile devices limit by their storage, processing powers and battery life. Cloud computing is an emerging technology that provides powerful computing resources such as networks, storage, processing power, servers, software and applications. With the increasing demand of Mobile users for powerful computing recourse cloud computing is integrated to mobile environment and called MCC. Emergence of MCC brings the new and excited application and services to mobile users, increased ease of integration, anytime-anywhere access to business applications and collaborative services, rich user experiences, and an explosion of new services [7]. There are various challenges in mobile computing environment focused in various research studies including battery life saving, storage, network bandwidth, heterogeneity, security and privacy. The integration of cloud computing in mobile environment overcome the challenges and issues related to performance, environment, and security which are the most general concerns in mobile computing environment. Fig. 2 shows the architecture of MCC.

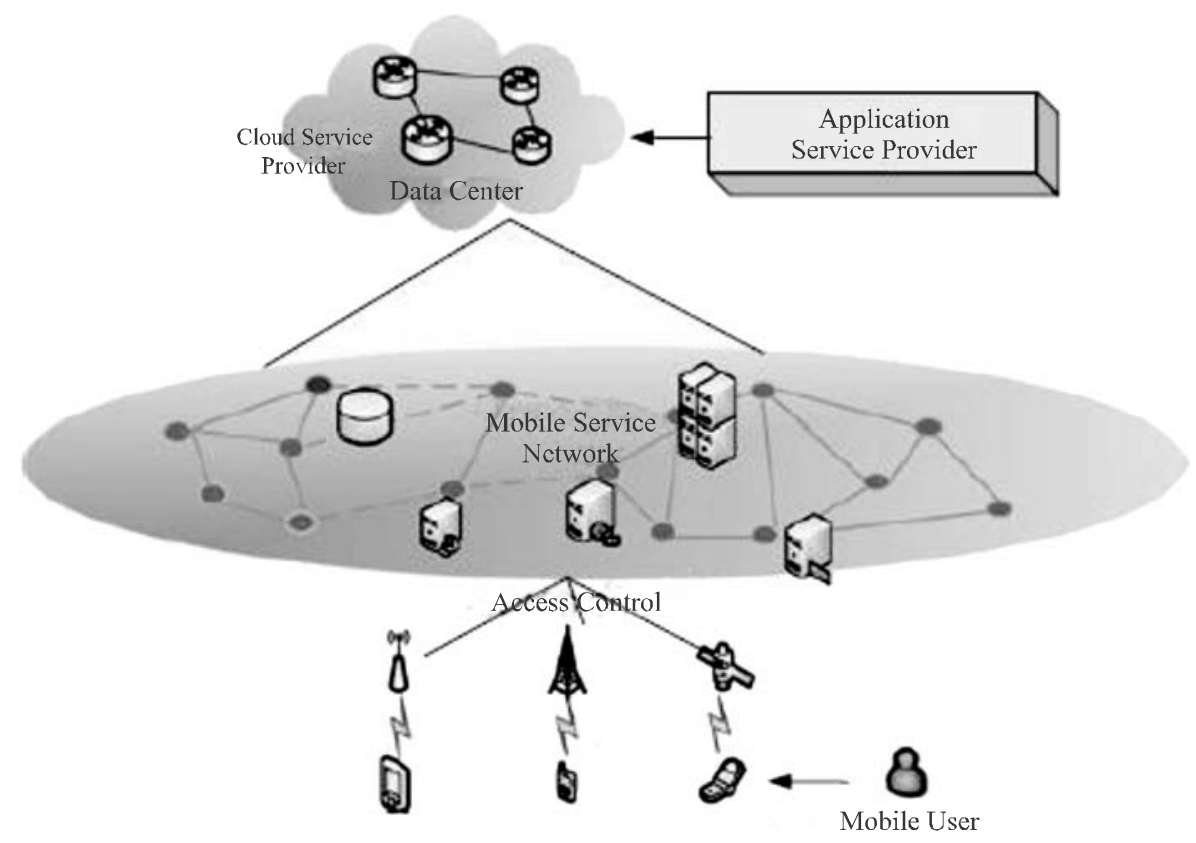

FIG. 2. ARCHITECTURE OF MOBILE CLOUD COMPUTING

Mehran University Research Journal of Engineering \& Technology, Volume 35, No. 3, July, 2016 [p-ISSN: 0254-7821, e-ISSN: 2413-7219] 


\subsubsection{Non Touch Interfaces}

One the most attracting technology trends are non touch interfaces for mobile devices and large displays as well. Mobile devices user already familiar with no touch interfaces such as voice recognition applications. Microsoft's Kinect [27], Apple's Siri [28] and Google's Project Glass [29] are the most latest and excited examples of non touch interfaces. Non touch interfaces are used to hands free access of information on mobile devices. Sensor and camera technology advancements leads towards sophisticated no touch interfaces for daily life activities. Microsoft Kinect gives the senses such as eyes, ears and brain to computers. Kinect uses advanced entertainment technology to respond to the sound of your voice. Just say some word and kinect reveal a series of voice commands. If we playing a game using Kinect with Xbox whether we a gamer or not we can play games using our body gestures. Kinect is providing a non touch interface it will recognize human and access it's Avatar. If we have to kick then kick and we have to jump then jump no need to joystick or other gaming input device (Kinect for Windows). Another non touch interface is Apples' Siri. It is voice recognition based mobile application that facilitates user of Apple iPhone, iPad, and iPod touch to perform their activities on device using voice. Apple's users can send messages; make calls, schedule meetings and appointments using their voice. It is enough smart to identify and choose appropriate app for a requested task. It plays the songs you want to hear, gives you directions, wakes you up, even tells you the score of last night's game.

User communicate interact Siri without touching the device and direct Siri to do things by talking the way he talks. Siri understands what you say, memorize and reminds user what he instructs as reminder, it not only understand what user say it also know what user mean, it question to the user and even talk to the user. In short it is a good non touch interface for the user of Apple [28]. Disaster response phase or rescue operation is a hand and eye busy environment with massive amount of information coming from multiple dimensions. In this type of work information gathering with minimum loss is a challenge issue. Non touch interfaces can play its critical role in information handling and knowledge management.

\section{EMBEDDINGDISASTERMANAGEMENTINTO TECHNOLOGIES INHAND}

According to the above defined statistics in account of mobile devices penetration and popularity it is clear that mobile computing future is brighter than today. Rapid development and advancement in wireless technologies including WiMax and WiFi giving the opportunity of availability of internet anytime and anywhere, while the usage of mobile devices are in fashion and need of time because everything is going to mobile. By using mobile devices like smart phones, PDAs and Tablets, most of the time users are connected and surfing to the internet and doing their activities without worrying about their physical connections and cables. Basically mobile computing is the combination of three major components including Hardware (Mobile Devices like Smartphone and Tablets), Software (various available mobile based applications) and communication [30]. Mobile based applications are frequently used in variety of human life activities like shopping, healthcare, entertainment, sports, disaster management, education, gaming and social networking etc. in recent years there has been increasing interest in mobile technology and mobile based application in divers domain both in research and industry. There is a variety of mobile computer systems available in healthcare, Sports, Fitness, business sector, supply chain management, customer relationship management, vendor managed inventory [31]. Along with all the above defined human being concern disaster management is the new and highly considerable domain for adopting mobile technology sophistication. Most of the latest and emerging technologies including ICT, mobile technology, GPS, Bluetooth, Wireless sensors, IoT, wearable technologies has the potential to solve many challenging issues of disaster management domain.

Mehran University Research Journal of Engineering \& Technology, Volume 35, No. 3, July, 2016 [p-ISSN: 0254-7821, e-ISSN: 2413-7219] 


\section{MOBILITY SOPHISTICATION IN REAL LIFE SCENARIO}

A real life problem means the activity or tasks of routine life. This may be a simplest task or it may be a complex activity. Technologies specially ICT and Mobile Technology are playing increasing role and providing great assistance in conducting these activities and tasks. By using these technologies these real life activities are performing in less amount of time, without bothering the time and space limitations, with more efficient and effective manner and with the advantage of transparency and flexibility of the process. There are some simple examples of MT applications which are frequently using in our routine life.

(i) Vehicle Verification is a time consuming and tedious task before the implementation of the ICT and MT applications. If somebody needs vehicle verification then he should go to the excise and taxation department physically and verified the vehicle. Now excise department of Pakistan launches an official web portal as well as mobile app for checking the vehicle registration and verification. These technological solutions minimize the time the process, no queue, no wait and no need to physically the visit of the excise office. One more great advantage of this solution is that these services are available round the clock so user can feel free to access these services on his mobile device beyond the time and space limitations.

(ii) Election Commission of Pakistan announced SMS based voter verification services. Now every Pakistani can verify his vote and also find out the electoral area of his vote just sending his CNIC (Computerized National Identity Card) number to 8300 as a SMS. In response of this SMS he got his CNIC Number, Electoral Area, i.e. District, Tehsil and city/town/village Block Code, Serial Number. This service solves a really big issue of voters and save huge amount of time which is wasted in finding voters eligibility manually.

(iii) NADRA (National Database and Registration Authority) of Pakistan launches a SMS based Mobile service with the help of PTA (Pakistan Telecommunication Authority) for the verification of CNIC. Using this service a user sends his CNIC number by SMS to 7000. In response of his SMS he got the verification of his CNIC and also knows whether there is any duplicate of his CNIC exists or not.

Above are the some real examples of mobile technology sophistication. These are the most common and general examples of frequently using MT based services in Pakistan. Advances of MT give the opportunity in near future to solve more challenging issues of human real life. The growing technology trends discussed in section 1.1 has the potential to solve various real life problems in near future. Most of human concerned domains like healthcare, business, shopping, entertainment, public services and emergency management are most determined domain to adopt and implement mobile technology sophistication.

This research focuses disaster management as a potential domain to implement MT sophistication. Disaster's increasing frequency and intensity drown the consideration of researcher and practitioner to incorporate latest and emerging technologies to solve issues and challenges in disaster management activities from early warning alerts to recovery and rehabilitation. Following are some future technologies and future vision of mobile technology sophistications in disaster management.

\subsection{Future Technologies}

The pace of development and advancements of technologies including ICT, MT, wireless networks technology and sensor devices is too fast. This development of technologies and their emerging trends 
creates opportunity for various research domains, industries, business, banking, public service, healthcare, education disaster management etc. to get maximum benefits of these technologies and their applications.

\subsection{Everybody and Everything Connected}

In future every object have embedded sensor, computation power and an IP through which these object are interconnected and somehow disseminating information to each other. People having smart objects also connected to each other as well as with other objects and sharing information. This scenario helps in future disaster management system by automated information handling and sharing among people and objects. When every have a embedded sensor then sensing and monitoring of environment and climate changes can be done at individual levels and in case of any emergency situation early warning messages and alerts can automatically disseminated to the relevant people by sensing their geo locations. During disaster response phase, this interconnectivity of people and object can simplify search and rescue operations. Rescue workers can easily locate the victims and also track them with the help of their GPS enabled smart objects and mobile devices.

\subsection{Smart Cities become Reality}

Houses and homes equipped with the sensor devices. These smart devices can be accessed on mobile devices and controlled remotely even from large desistance using wireless network technology like Wi-Fi. In near future when smart cities and smart homes concept become more mature and established then this will make disaster management activities and process. With the help of smart home and cities it will become more efficient to monitor and controlling of home appliances which save energy, reduce disaster like fire chances, alert family members within time in case of any emergency situation. Smart cities concepts simplify the information dissemination process and make it automated and task oriented. If there is a fire disaster the smart home is capable to inform fire department first and in case of a medical emergency it will call ambulance or a doctor.

\subsection{Mobile Money}

With the advancement of technologies like MT and ICT many old concepts and processes are going to replace and new technological models will take place which provide ease and comforts to human beings and enhance the activities in different domain of human life concerns. In the last couple of years plastic money replaced the paper money. It is predicted that by 2020 paper currency as well as plastic money will disappear and mobile money will take place in most of the advance countries. The concept of mobile money is that instead of paying cash, giving checks or swapping credit cards a consumer can use his mobile phone for payment for his shopping, purchasing or having verity of services. The World Bank predicts that by 2020 , mobile money could impact the lives of more than 2 billion people in developing countries, heralding a new era of financial services, and hence, lifting them out of poverty. The mobile phone penetration outnumbers the bank account penetration. For every one bank account holder, there are three mobile phone owners.

In a disaster scenario, there is an urgent need of money and funds for the recovery of the victims and for providing basic life needs like medicine, food, water etc. collection of donation or sending donation is a time taken activity. For minimizing the fund transfer time mobile money will be the best solution for rapid transaction and speedup the process of recovery of the victims. Local, national and international donors can donate immediately using mobile money and the victims and the relief organizations instantly got the money for relief work. Mobile money fastest the fund transfer process, make it transparent and more reliable in disaster scenario.

\subsection{Wearable Computer Devices}

A wearable computer device is also a growing technology trend. These devices are increasingly using in many human concern domains like healthcare, body fitness, sports and many more. These devices can also helpful in disaster management domain and can provide great assistance in 
conducting many disaster management related activities like search and rescue operations. Rescue workers can use helmets with camera and GPS enabled options they can easily capture live videos of the surrounding and can transfer live video to their control room for better assistance and rescue help. Wearable wristbands can continuously disseminate vital signs of the rescue worker to monitor his health and conditions and avoid any misshape or at least inform to other teams members and control room in case of any emergency situation like breathing problem, change of heart rate, deficiency of oxygen, suffocation etc which may be danger for the rescue worker. Location and tracking of victim using GPS enabled device including wrist band or helmet can update the status of rescue worker automatically. Wearable sensor devices can sense the surrounding and helps in saving rescue workers life during rescue operation. these devices record and share environment conditions like increase in temperature, smoke, chemical etc. with his team to aware the situation of the region.

\subsection{Language Interoperability}

During disaster response phase language. The future mobile devices are flexible for the translation of Multilanguage's according to user needs and comforts. When someone in country or region where the specking language is different from his or her native language then it is difficult to communicate his or her words to the local community. MT can solve this problem an there is already some translators applications are available in the mobile devices which can translate from one language to another language. A mobile translator is an application for smart devices that can instantly translate words or phrases in a great number of different languages. The simplicity and the ease recommend them as "a must have" when one visits another country. So, stuff your phone with online and offline applications that can help you break down the language barrier that separates people from other countries. According to the Serban [32] there are variety of mobile translator applications are available. Following are the top most mobile translator applications.
(1) Google Translate

(2) Bing Translator

(3) Jibbigo

(4) iTranslate

(5) Voice Translate Pro

(6) Tourist language learn \& speak

(7) Navita Translator

(8) SayHi Translate

(9) Lonely Planet Offline Translator

(10) Trippo Mondo Voice Translator

According to the [33-35] the most popular languages among the mobile app users are:

(1) English (28\%)

(2) Spanish (15\%),

(3) Simplified Chinese (12\%)

(4) Japanese (5\%)

(5) $\quad$ Korean $(4 \%)$

(6) French (4\%)

(7) $\operatorname{German}(3 \%)$

(8) $\quad$ Italian $(2 \%)$

(9) Portuguese (2\%)

Decision for the best target language for translation is the most crucial issue for the mobile application developer. It is predicted that by 2020 this language interoperability will be resolved and Multilanguage translators are available in mobile devices that seamlessly translate from source natural language to different target languages. In disaster management language is also a barrier for communication instruction and communication between victims and volunteers in case of different languages. It is common that in large scale disasters volunteers comes across the country or even around the world. They speak and understand different languages. To resolve this language issue mobile technology can play an important role and provide multi language interoperability. The volunteers 
come from different regions of the world cannot bother language barrier; their mobile devices are smart enough to translate their language into victims' language and vice versa. The implementation of language interoperability increase the efficiency of rescue and relief work as volunteers of different regions can communicate easily with each other and communicate with victims too. It is redicted that by the year 2020 technical trends such as smart cities, context awareness devices, display and mobile devices everywhere that connects to everything, human centric computing and continuous access to massive amount of data will make city workers and citizens more efficient at work and continuously connected to family, friends and information [34].

\section{CONCLUSION}

Rapid advancement of technology especially in ICT and MT provides the opportunity to replace the complex and time consuming process and procedures of real life problems of human being. MT is the fastest adopting technology in the current time; rapid advancements in MT, wireless networks and sophisticated mobile based software development give opportunities to use MT in real life scenarios including kid's education to transferring funds. MT is enhancing the human life activities by providing anywhere, anytime availability, make easy to use and gives flexibility. Future of MT is more promising than it delivered today even a common man can't imagine executing his routine life without mobile devices. Opening home or office door without using key, driving the cars without, charging devices wirelessly, paying shopping bills without user intervention, check in and checkout without going to registration desk of a hotel these all are and many more are the promising of near future MT. Disaster Management is one of the most focused domains for adopting and implementing latest and emerging technology trends. Many of the disaster management process, procedures, activities and operations can be enhanced by using these latest technologies and their sophistications.

\section{ACKNOWLEDGEMENT}

The authors would like to express their thanks to the Department of Computer Science, Federal Urdu University of Arts, Sciences \& Technology, Karachi, Pakistan, for providing computing facilities and access of online research journals to pursue this study.

\section{REFERENCES}

[1] Deepak, G., and Pradeep, B.S., "Challenging Issues and Limitations of Mobile Computing”, Volume 3, No. 1, pp. 177-181, 2012.

[2] Gasimov, A., Tan, C.-H., Phang, C.W., and Sutanto, J., "Visiting Mobile Application Development: What, How and Where", Internaltional Conference on Mobile Bussiness, pp. 74-81, 2010.

[3] Ladd, D.A., "Trends in Mobile Computing within the IS Discipline: A Ten-Year Retrospective”, Volume 27, No. 1, 2010

[4] Shafiq, F., and Ahsan, K., “An ICT based Early Warning System for Flood Disasters in Pakistan", Research Journal of Recent Sciences, Volume 3, No. 9, pp. 108-118, 2014

[5] Shafiq, F., Ahsan, K., Nadeem, A., Sarim, M., Shaikh, A.B., and Siddiq, M., "Role of ICT in Climate Change Monitoring/ : A Review Study of ICT based Climate Change Monitoring Services", Research Journal of Recent Sciences, Volume 3, No. 12, pp. 123-130, 2014.

[6] Banks, D., "10 of the Biggest Trends in Technology for 2014”, 2014. [Online]. Available: http:// www.huffingtonpost.com/damon-m-banks/10-of-thebiggest-trends-_b_4725708.html.

[7] IEEE Computer Society, "Top Technology Trends for 2014", Available: http://www.computer.org/portal/web/ membership/Top-10-Tech-Trends-in-2014. [Accessed: 14-Jan-2001].

[8] Burrus, D., "Eight Pathways of Technological Advancements", 2014.

[9] McGee, M.K., "New Gadgets Monitor Your Health And Fitness", 2012 [Online] Available: http:// limitlesstechnology.com/gadgets-monitor-health-fitness.

Mehran University Research Journal of Engineering \& Technology, Volume 35, No. 3, July, 2016 [p-ISSN: 0254-7821, e-ISSN: 2413-7219] 
[10] Pappas, S., "Will Wearable Tech Bring Humanity a 'Sixth Sense?", 2014. [Online]. Available: http:// www.livescience.com/42490-wearable-biosensortechnology.html.

[11] Park, S., and Jayaraman, S., "Enhancing the Quality of Life through Wearable Technology", IEEE Engineering in Medicine and Biology Magazine, Volume 22, No. 3, pp. 41-48, 2003.

[12] Lukowicz, P., Kirstein, T., and Troster, G., "Wearable Systems for Health Care Applications", Methods of Information in Medicine, Volume 43, No. 3, pp. 232$238,2004$.

[13] Bonato, P., "Advances in Wearable Technology and Applications in Physical Medicine and Rehabilitation", Neuro Engineering and Rehabilitation, Volume 2, No. 1, pp. 2, 2005 .

[14] Bonato, P., "Wearable Sensors/Systems and their Impact on Biomedical Engineering", EEE Engineering in Medicine and Biology Magazine, Volume 22, No. 3, pp. 18-20, 2003.

[15] Zhu, C., and Sheng, W., "Wearable Sensor-Based hand Gesture and Daily Activity Recognition for RobotAssisted living, Systems, Man and Cybernetics, Part-A", IEEE Transactions on Systems and Humans, Volume 41, No. 3, pp. 569-573, 2011.

[16] McCann, J., Hurford, R., and Martin, A., “A Design Process for the Development of Innovative Smart Clothing that Addresses End-User Needs from Technical, Functional, Aesthetic and Cultural View Points", $9^{\text {th }}$ IEEE International Symposium on Wearable Computers, pp. 70-77, 2005.

[17] Baber, C., Smith, P., Cross, J., Zasikowski, D., and Hunter, J., "Wearable Technology for Crime Scene Investigation", $9^{\text {th }}$ IEEE International Symposium on Wearable Computers, pp. 138-141,2005.

[18] Haniff, D.J., and Baber, C., "Wearable Computers for the Fire Service and Police Force: Technological and Human Factors", $16^{\text {th }}$ International Symposium on Wearable Computers, IEEE Computer Society, pp. 185-185, 1999.
[19] Meissner, A., Luckenbach, T., Risse, T., Kirste, T., and Kirchner, H., "Design Challenges for an Integrated Disaster Management Communication and Information System", $1^{\text {st }}$ IEEE Workshop on Disaster Recovery Networks ,Volumme 24, 2002.

[20] Kleiner, A., Behrens, N., Kenn, H., Computing, W., and Multiagent, M., "Wearable Computing Meets Multiagent Systems/ : A Real-World Interface for the RoboCupRescue Simulation Platform", $1^{\text {st }}$ International Workshop on Agent Technology for Disaster Management, pp.116-123, 2006.

[21] eBizMBA, "Top 15 Most Popular Social Networking Sites”, 2013. [Online]. Available: http:// www.ebizmba.com/articles/social-networking-websites.

[22] Merchant, R.M., Elmer, S., and Lurie, N., "Integrating Social Media Into Emergency-Preparedness Efforts", The New England Journal of Medicine, Volume 365, No. 4, pp. 289-291, 2011.

[23] Lampert, A., Technologies, P., Cameron, M., Robinson, B., Power, R., and Centre, C.I.C.T., "Using Social Media to Enhance Emergency Situation Awareness", IEEE Intelligent Systems, Volume 6, pp. 52-59, 2012.

[24] Gao, H., Barbier, G., and Goolsby, R., "Harnessing the Crowdsourcing Power of Social Media for Disaster Relief”, IEEE Intelligent Systems, Volume 26, No. 3, pp. 10-14, 2011.

[25] Sutton, J., Palen, L., and Shklovski, I., "Backchannels on the Front Lines: Emergent Uses of Social Media in the 2007 Southern California Wildfires", Proceedings of $5^{\text {th }}$ International ISCRAM Conference, pp. 624-632. Washington, DC, 2008.,

[26] Yates, D., and Paquette, S., "Emergency Knowledge Management and Social Media Technologies: A Case Study of the 2010 Haitian Earthquake", International Journal of Information Management, Volume 31, No. 1, pp. 6-13, 2011.

[27] Microsoft, "Kinect for Windows", 2014. [Online]. Available: http://www.microsoft.com/en-us/ kinectforwindows. [Accessed: 14-Jun-2025].

[28] Siri, "IOS7", 2014. [Online]. Available: https:// www.apple.com/ios/siri/. 
[29] Google, "The Glass Explorer Program”, 2014. [Online]. Available: https://www.google.com/glass/start.

[30] Qi, H., and Gani, A., "Research on Mobile Cloud Computing/: Review Trend and Perspectives", $2^{\text {nd }}$ IEEE International Conference on Digital Information and Communication Technology and it's Applications, pp. 195-202, 2014

[31] Wu, I.-L., Li, J.-Y., and Fu, C.-Y., "The Adoption of Mobile Healthcare by Hospital's Professionals: An Integrative Perspective", Decision Support Systems, Volume 51, No. 3, pp. 587-596, 2011.
[32] Serban, A., "10 Best Translating Apps for Mobile Devices Online \& Offline”, 2013. [Online]. Available: http:// techpp.com/2013/06/05/best-translating-apps. [Accessed: 14-Jun-2029].

[33] Sozonova, I., “Top 12 languages for Translation”, 2013. [Online]. Available: http://www.icanlocalize.com/site/ 2013/10/what-are-the-top-languages-for-translation.

[34] Hedlund, J., "Smart City 2020 Technology and Society in the Modern City", 2012. [Online]. Available: http:// www.microsoft.com/global/sv-se/offentlig-sektor/ PublishingImages/Smart_city_2020.pdf. [Accessed: 14Jun-2029]. 2012. 